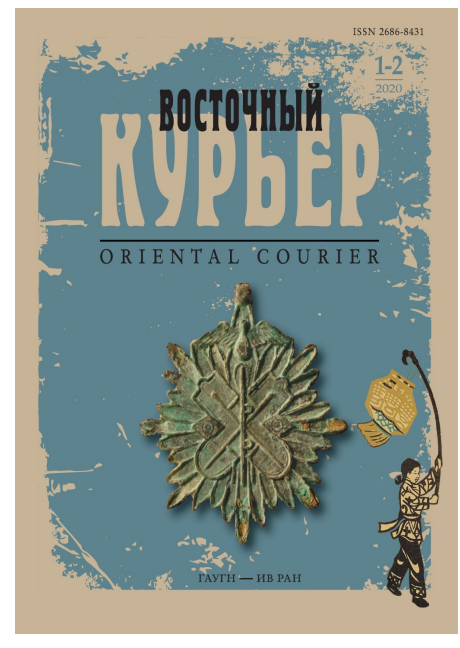

Восточный курьер. 2013-2023

ISSN 2686-8431

URL - http://oriental-courier.ru

Все права защищены

Выпуск № 1-2 Том . 2020

\title{
Особенности японской экономической коррупции
}

\section{Мельник Анастасия Андреевна}

Государственный академический университет гуманитарных наук (ГАУГН) Российская Федерачия, Москва

\section{Аннотация}

В статье проводится анализ основных видов коррупции в Японии и рассматривается возникновение современной послевоенной коррупционной партийно-бюрократической системы. Дан краткий обзор текущего состояния, механизмов коррупционной деятельности и ее негативного воздействия на экономику современной Японии, а также отношение современного японского общества к деловой и бытовой коррупции.

Ключевые слова: коррупция, железный треугольник, амакудари, кансэй данго

Дата публикации: 31.07.2020

\section{Ссылка для цитирования:}

Мельник А. А. Особенности японской экономической коррупции // Восточный курьер. - 2020. - Выпуск № 1-2 С. 29-37 . URL: https://orientalcourier.ru/s268684310010362-6-1/. DOI: 10.18254/S268684310010362-6

\section{Что такое «коррупция»?}

2 Как известно, коррупция представляет собой сложное социальное явление, пронизывающее многие сферы общественной жизни: социальную, политическую, экономическую и т.д. В настоящее время изучению и решению этого феномена уделяется значительное внимание - как со стороны государства, так и в рамках исследований независимых специалистов и неправительственных организаций. 
3 Понятие «коррупция» получило известность благодаря римскому праву, где оно обозначало некое противоправное действие: порчу, разрушение и подкуп. Таким образом сформировался отдельный и самостоятельный термин, применявшийся в тех случаях, когда в действии участвовало не менее двух лиц, целью которых было «повреждение» процесса управления делами [Астафьева, 2005 , c. 34].

4 В наше время эксперты Совета Европы разработали, возможно, наиболее полное определение: коррупция - это «взяточничество, подкуп и любое другое поведение лица, наделенного ответственностью в публичном или частном секторе, которое нарушает свои обязанности, вытекающие из его публичного статуса как публичного лица, частного наемного работника, независимого агента или другого статуса подобного рода, и нацелено на получение неправомерных преимуществ любого рода для себя или другого лица» [Швец, 2000, с. 67].

5 Принято выделять два вида коррупции - экономическую и политическую. В статье сделан фокус на экономической коррупции в Японии.

6 Экономическая коррупция, как полагает российский ученый Ю. А. Нисневич, включает в себя все, что связано с материальными вопросами. Другими словами, характер экономической коррупции проявляется в том, что она является следствием экономических отношений, и способна напрямую влиять на их развитие - распространение коррупции, несомненно, служит поводом для зарождения целого спектра негативных процессов в экономике страны, что в свою очередь приводит к ряду нежелательных последствия.

7 Экономическую коррупцию можно разделить на бытовую и деловую.

8 Особенность бытовой коррупции заключается в том, что гражданин посредством общения с представителем государственных структур или чиновником получает за деньги определенные услуги на незаконной основе.

9 Деловая коррупция имеет место, когда бизнесмен вступает в контакт с представителем власти среднего звена или чиновником. В таком случае происходит следующее: бизнесмен путем воздействия на чиновника добивается продвижения собственных экономических интересов, приобретения определенной экономической выгоды, получения доступа $\kappa$ необходимы ресурсам и т. д. В результате бюрократический аппарат начинает работать уже не на государство, а в интересах частных предприятий, получая при этом материальное вознаграждение ${ }^{1}$.

10 В японском языке слово коррупция (осёку), записывается двумя иероглифами: «污》— г гязь и «職》— должность; работа.

11 Подобное сочетание иероглифов можно объяснить, обратившись к древней религии, зародившейся в Японии как учение еще в VII-VIII вв., - к синтоизму. Дело в том, что древние японцы разделяли всех людей на «чистых» и «нечистых». Для добропорядочного человека «грязь» неприемлема, и именно поэтому в синтоизме до сих пор существуют традиционные обряды очищения [Davis, Osamu, 2002, p. 153]. 
Стать участником коррупционного правонарушения означает стать «грязным», потерять лицо. Для японца, позиционирующего себя в общественных отношениях не как отдельная личность, а скорее, как часть единого социума, для которого «социальное лицо значит очень много», быть «грязным» равносильно отчуждению от общества [Шкапа, 2004, с. 169].

13 Если говорить об официальном понятии термина «коррупция», то в японском законодательстве она определяется именно как противоправное действие, подразумевающее умышленное использование должностным лицом служебного положения с целью получения имущественных или же неимущественных благ любой формы².

14 Согласно Уголовному Кодексу Японии, обязательным признаком коррупционного действия по японским закону является взятка, при этом само понятие взятки в Уголовном Кодексе не раскрывается [Басова, 2005, с. 53]. Это напрямую связано с определенной спецификой восточной культуры, отразившейся на всех сферах социальной жизни японского народа.

15 Культура таких стран Дальнего Востока, как Китай и Япония, формировалась под господствующим влиянием этико-философских учений. Так, конфуцианство видело государство как «большую семью», где преподнесение подарков старшим считалось частью народной традиции и нормой поведения. Вместе с политической системой Япония позаимствовала у Китая и обряды, связанные с преподношением даров. Возможно, именно этим историческим фактом можно объяснить отсутствие четкого определения взятки. Как отмечает С. А. Полхов, «в докапиталистической Японии дары, подношения и взятки не различались между собой» [Полхов, 2014, с. 138].

16 На сегодняшний день не существует ни одной страны, где бы отсутствовала коррупция. Исследователи солидарны во мнении, что коррупционная деятельность зарождается именно там, где «существует власть и крутятся большие деньги» ${ }^{3}$. И притом что все больше стран направляют усилия на борьбе против коррупции, для других этот неистребимый феномен остается способом существования. «Сегодня в мире 194 суверенных государства, из них только 22-25 могут похвастаться низким уровнем коррупции, во всех остальных он либо средний, либо очень высокий, что во многом связано с разницей между политическими режимами» ${ }^{4}$.

17

\section{Особенности японской коррупции и причины ее возникновения}

18 Согласно данным индекса восприятия коррупции, ежегодно публикуемому организацией по изучению и борьбе с коррупцией Transparency International, в 2015 г. Япония занимала 18-е место среди 168 стран, вошедших в исследование. Среди стран Азии Япония стоит на втором месте после Сингапура, известного весьма низким уровнем коррумпированности властных структур ${ }^{5}$. Столь высокий результат объясняется тем, что Япония на протяжении уже многих десятилетий предпринимает активные меры по борьбе с проявлениями коррупции, ведь согласно данным «Белой книги Главного полицейского управления Японии», ежегодно в стране возбуждается около 50-60 подобных дел 6 . 
В период правления императора Мэйдзи (1868-1912 гг.) чиновничество было еще слабо коррумпированным: статус бюрократа был высоким и престижным, а доход постоянным. Однако проблема коррупции в Японии обострилась в послевоенное время, когда в 1955 г. к власти пришла ЛиберальноДемократическая партия (ЛДП), остающаяся «у руля» страны и в настоящий момент. Фактически, именно ЛДП запустила механизм, способствовавший зарождению в стране сложной структуры распределения власти: государство считалось «унитарным субъектом», в котором все могущество было сконцентрировано в тесном «железном треугольнике» между политиками, бюрократией и бизнесом [Сравнительное проведение... 2010, с. 76].

20 С усилением значимости политической партии увеличивалось и еe влияние на чиновников, благодаря чему представители бюрократии начали активней занимать должности в высших эшелонах власти. Проявление этой тенденции стало значительно сильней, когда участилось перемещение чиновников из государственного аппарата в партийный, где они становились видными политическими функционерами [Молодякова, 2000, с. 65].

21 К сформировавшейся парадигме отношений «политики - бюрократия» постепенно органично присоединился и бизнес-сектор, обеспечивавший поддержку политических представителей за счет наполнения их финансовых фондов. Таким образом и выстроилась система сотрудничества, при которой бизнес обеспечивал поддержу политиков. В интересах бизнеса политики могли оказывать влияние на деятельность бюрократического аппарата. Следовательно, у бизнеса появлялась возможность в определенной степени контролировать аппарат исполнительной власти, ведомства и министерства, а также осуществлять частичный контроль и над выборными органами. Бюрократы же, расставшись с государственной службой, нередко занимали высшие посты в иерархии правящей партии. Благодаря их связям с госаппаратом они могли воздействовать на основные приоритеты вырабатываемого правительством курса в отношении развития страны, учитывая интересы крупного бизнеса [Сравнительное проведение... 2010, с. 74].

22 Таким образом, бытовая коррупция получила в Японии весьма малое распространение, в гораздо же большей степени развилась коррупция деловая. Это подтверждают и авторитетные российские исследователи. Как отмечает бывший посол России в Японии А. Н. Панов, коррупции на бытовом уровне в Японии и «вовсе не бывает, а бывает там, где есть большие деньги и власть»7.

23 Считается, что еще одним толчком для зарождения коррупционной деятельности в Японии стала своеобразная японская система государственной службы. Дело в том, что в Японии система госслужбы предполагает достаточно медленное продвижение по карьерной лестнице и, согласно Закону «о предельном возрасте», относительно ранний (с учетом средней продолжительности жизни в Японии) уход на пенсию - 64 года [Реформирование системьл государственного управления... 2005, с. 180]. Все это способствовало формированию схемы, получившей название амакудари. 
Термин «амакудари», пришедший из синтоизма, изначально обозначал «схождение божества на Землю». Дословно он переводится как «сошествие с небес». Интересно, что сейчас под «небесами» понимается именно бюрократический аппарат ${ }^{8}$. В современной трактовке амакудари означает процесс перехода высокопоставленных бюрократов (по достижении предельного возраста пребывания на государственной службе) на работу из правительственного аппарата в частную компанию.

25 Известные российские исследователи Э. В. Молодякова и С. А. Полхов полагают, что амакудари действительно способствовала развитию коррупционной деятельность в сферах экономики и политики [Молодякова, 2000, с. 71]. Однако же А. Н. Панов утверждает, что это «не коррупция, а изменение места службы, которое не воспринимается в Японии, как что-то порочащее» ${ }^{9}$.

26

\section{Система «амакудари»}

27 С. А. Полхов объясняет свою точку зрения следующим образом. Частные компании находят сотрудничество с чиновниками, ушедшими в отставку, весьма выгодным, поскольку даже по окончанию государственной службы у тех остаются ценные политические связи в высших кругах: «В итоге, зарождается тесное переплетение бюрократии и частных компании» ${ }^{10}$. Другими словами, формируются двусторонние отношения, несущие в себе определенную пользу для обеих сторон.

28 Действительно, в Японии принято, чтобы крупные и ведущие компании принимали на работу отставных бюрократов, обеспечивая, таким образом, определенную защиту и преимущества, помогающие при выработке правительственными структурами решений по тем или иным вопросам, интересующим бизнес.

29 Если говорить о спонсорском финансировании политических избирательских кампаний, где в качестве главного спонсора выступают частные корпорации, то в Японии проведение подобных мероприятий является делом весьма затратными. Тем не менее они служат отличной базой для создания близких отношений между частным бизнесом и претендентами на парламентский мандат. Кандидат, победивший на выборах, способен вознаградить спонсорские компании, надавив на чиновников или создав максимальные условия для получения ими важных государственных заказов и т. д.

30 Одним из негативных последствий системы амакудари, без сомнения отражающимся и на экономике страны, видится тот факт, что она приводит к неэффективному использованию государственных средств: существует практика образования полугосударственных компаний, в том числе, с целью получения крупных сумм от правительства для отставных чиновников и их помощников ${ }^{11}$. В 2009 г., согласно подсчетам Демократической партии Японии, государственное финансирование корпораций, поддерживающих практику амакудари, в общей сумме составило 700 млрд. иен ${ }^{12}$. 
Таким образом, схема перехода из государственной службы в частный бизнес выгодна не только нанимающей компании, но и самому чиновнику, вышедшему в отставку — но не экономической системе страны в целом.

32 Коррупция в Японии может представляться не только традиционно в виде денежного подкупа, но и в виде подношения подарков. Можно сказать, что система амакудари является еще одним воплощением японской экономической коррупционной деятельности, определяющегося взаимовыгодными двусторонними отношениями.

33 Возможно, описанная система не всеми в Японии воспринимается как нечто порочное. Тем не менее ряд политических объединений, включая Демократическую партию Японии, считают, что амакудари способствует распространению коррупции, и, подтверждая свои доводы анализом различных статистик и подсчетами данных, активно пытаются бороться с ней.

34 Не менее важным доказательством того, что система амакудари связанна с коррупцией, является и то, что именно эта система стала причиной возникновения проблемы сговоров при проведении государственных тендеров, которую в Японии принято называть кансэй данго.

35

\section{Коррупционная схема кансэй данго}

36 Получившая распространение в Японии практика кансэй данго представляет собой сговор между частным бизнесом и чиновниками, в рамках которого компаниям, претендующим на получение государственных подрядов (особенно, строительным), становится доступной закрытая информация о тендере, включая предложения других конкурентов ${ }^{13}$. Эта коррупционная схема широко задействовалась в послевоенное время и даже воспринималась как нечто само собой разумеющееся. Нередко эти частные фирмы рассматривались японскими чиновниками как потенциальное место работы после завершения государственной службы (прослеживается связь с амакудари).

37 С. А. Полхов отмечает, что в Японии «вмешательство государства в экономику проявляется в том, что огромные средства выделяются на общественные работы - например, строительство дорог. Частные компании, которые эти дороги строят, тесно связаны с чиновниками профильного ведомства. Конкурс на поиск подрядчиков, разумеется, проводится, но чисто формально» ${ }^{14}$.

38 Нередко в эти схемы оказываются вовлечены и политические круги. Тогда незаконные преференции могут быть предоставлены компаниям, являющимся основными финансовыми источниками политических фондов.

39 Хотя с начала 1990-х гг. в рамках общей тенденции борьбы с коррупцией в Японии начали вырабатываться меры, целью которых было полное устранение системы кансэй данго, проблема сохраняет актуальность и в настоящее время. Согласно опубликованным данным, количество уголовных дел, возбуждаемых в связи с этим видом коррупционной деятельности, ежегодно составляет в Японии около $10-15^{15}$. 
В качестве конкретных примеров можно привести имевший место в 2006 г. ряд судебных процессов, в ходе которых акционеры судились с руководителями корпораций из-за подозрения последних в участии в подобных схемах, что, как считалось, наносило компаниям значительный ущерб.

41 В 2010 г. опубликована информация о том, что служащие Воздушных сил самообороны Японии уличены в подтасовке договоров о закупках, в 2012 г. разоблачили представителей Сухопутных сил самообороны Японии, предоставивших одной частной компании информацию о заявках на тендер о новом поколении вертолетов [Pickworth, Williams, 2012, p. 144].

42

\section{Подкуп иностранных должностных лиц}

43 Япония, без сомнения, может гордиться достаточно низким уровнем коррупции внутри страны. Однако, как известно, в других государствах антикоррупционная политика только набирает силу. Это формирует условия, в которых японские граждане могут оказаться участниками схем, предполагающих дачу взяток в рамках работы за рубежом с иностранными партнерами. Таким образом, можно выделить еще один вид коррупции, получившей распространение в Японии, — подкуп иностранных должностных лиц.

44 Проблема международных связей с другими странами заключается в том, что появляются возможности для коррупции за пределами Японии. При этом зачастую речь идет о получении доступа к ресурсам, которыми обладает другая страна.

45 Наглядный пример - получивший скандальную известность сюжет, когда японские рыболовные фирмы платили российским официальным лицам взятки, чтобы те не пресекали вылов минтая сверх установленной квоты в российских территориальных водах. Японские правоохранительные органы, выявившие эти случаи, предложили сотрудничество российской стороне в проведении расследования и на какое-то время запретили промысел фирмам, уличенным в даче взяток $^{16}$.

46

\section{Заключение}

47 Как полагают российские исследователи, особенность правительственной системы Японии заключается в более сильном, чем в других странах, элементе межведомственной разобщенности и внутриведомственном эгоизме. Широко распространено представление о том, что ведомства преследуют собственные цели, которые не обязательно коррелируют с общенациональными интересами (см.: [Внешнеполитический процесс в странах... 2011, с. 248]).

48 Действительно, государственный аппарат, пытаясь укрепить свою власть и при этом сохранить выгодные позиции, благодаря тесному сотрудничеству с частным сектором во многом способствовал распространению и укреплению коррупции в Японии. 
Официально считалось, что система амакудари, обеспечивавшая высокий уровень дохода чиновнику после отхода от государственных дел, являла собой неплохую систему сдерживания коррупции, поскольку обеспечивала высокую заработную плату. Однако по факту оказывается, что коррупционные действия заключаются в том, что с переходом на новое место работы чиновник в интересах компании активно задействует наработанные годами связи. Кроме того, в большинстве случаев оказывается, что чиновник выстраивал тесные отношения с деловыми кругами еще по мере продвижения в государственной службе.

50 Таким образом, формировались коррупционные отношения следующего типа:

51 - По мере восхождения чиновника по карьерной лестнице

52 Бизнес обеспечивал финансирование, продвижение избирательной кампании политика, имеющего связи в бюрократическом аппарате. Соответственно, кандидат, победивший в избирательной кампании, через чиновника обеспечивал государственные заказы, получение необходимой информации.

53 • После отхода чиновника от политических дел

54 Бизнес обеспечивал высокую должность и стабильный хороший заработок - чиновник обеспечивал определенную защиту и помощь благодаря наработанным на государственной службе связям.

55 Демократическая партия Японии, подвергая критике установившуюся «дуальную систему решений», которая, собственно, и приводит к формированию своеобразных «коррупционных смычек в железном треугольнике», активно пытается бороться с данной проблемой. С другой стороны, существуют опасения, что ограничение или устранение амакудари впоследствии может привести лишь к усилению коррупции.

56 В послевоенное время японское государство поставило цель достичь высоких результатов в развитии всей страны. Как результат, на сегодняшний день Япония считается одной из самых высокотехнологичных, экономически развитых держав со сравнительно низким уровнем коррупции.

Примечания:

1. Коррупция - излечимая болезнь? High School of Economy. URL: >>>> (дата обращения 08.04.16).

2. Опыт законодательного обеспечения общественного и парламентского антикоррупционного контроля в некоторых государствах мира. Сервер юридической информации. URL: $\geq>>>$ (дата обращения 08.04.16).

3. На «восходе» взяток не берут: Александр Панов о коррупции в Японии. PASMI.RU Первое Антикоррупщичонное CMИ. URL: $\geq>>$ (дата обращения 10.04.16).

4. Коррупция - излечимая болезнь? High School of Economy. URL: >>> (дата обращения 08.04.16).

5. Corruption Perceptions Index 2015. Transparency International. URL: \>> (дата обращения 26.04.16).

6. Хэйсэй 27 нэн кэйсацу хакусё токэйсирё (Белая книга Главного полицейского управления Японии за 2015 г. 
7. На «восходе» взяток не берут: Александр Панов о коррупции в Японии. PASMI.RU Первое Антикоррупщ̧ионное СМИ. URL: $\gg>>$ (дата обращения 10.04.16).

8. The Government of Modern Japan: The Japanese Bureaucracy. Retirement: Amakudari. Asian Topics. URL: $\geq>>>$ (дата обращения 10.04.16).

9. Опыт законодательного обеспечения общественного и парламентского антикоррупционного контроля в некоторых государствах мира. Сервер юридической информащии. URL: $\geq>>>$ (дата обращения 08.04.16).

10. Коррупция в японском исполнении. Свободная пресca. URL: svpressa.ru/society/article/53869/ (дата обращения 10.04.16).

11. От лидерства чиновников к лидерству политиков. Ассощиащчия японоведов. Межрегиональная общественная организация. URL: $\geq>>$ (дата обращения 08.04.16).

12. Минсюто но сейкенсейсаку манифесто 2009 (Государственная политика Демократической партии Японии). Официальный сайт Демократической партии Японии. $\gg>>$ (дата обращения 11.04.16).

13. Нюсацу данго надо канъёкои босихо ни цуитэ (О законе о противодействии сговору при проведении государственных тендеров). Комитет по обеспечению справедливых торговых сделок Японии. URL: www.jftc.go.jp/dk/kansei/kanyoboushi.files/kanseileaflet02.pdf (дата обращения 13.03.16).

14. Коррупция в японском исполнении. Свободная пресса. URL: svpressa.ru/society/article/53869/ (дата обращения 10.04.16).

15. Кансэйданго ва надзэ хэранай? Нюсацу футё кайхига мокутэкино «сингата» мо тодзё (Почему не сокращается число случаев кансэйданго? Новые формы сговора в целях недопущения аннулирования тендеров). Еэсенедельное издание Сюкан даямондо. URL: diamond.jp/articles/-/87077 (дата обращения 02.04.16).

16. Коррупция в японском исполнении. Свободная пресca. URL: svpressa.ru/society/article/53869/ (дата обращения 10.04.16).

\section{Библиография:}

1. Астафьева Т. А. Международно-правовой опыт борьбы с коррупцией. Молодые юристы - науке и практике. Владивосток: ПИППКРО, 2005. С. 30-45 [Astafyeva T. A. International Legal Experience in the Fight against Corruption. Young Lawyers to the Science and Practice. Vladivostok: PIPPKRO, 2005. Pp. 30-45 (in Russian)].

2. Басова Т. Б. Регламентация уголовной ответственности за должностные преступления: законодательный опыт России и Японии. Вестник ДВО РАН. № 4. 2005. C. 48-56 [Basova T. B. Regulation with Regards to Criminal Liability for the Official Misconduct: Legislative Experience of Russia and Japan. Journal of the FarEastern Branch, RAS. No. 4. 2005. Pp. 48-56 (in Russian)].

3. Внешнеполитический процесс в странах Востока. Под ред. Д. В. Стрельцова. М.: Аспект Пресс, 2011. - 336 с. [The Foreign Policy Process in the Eastern countries. Ed. D. V. Streltsova. Moscow: Aspect Press, 2011. — 336 p. (in Russian)].

4. Молодякова Э. В. Устойчивые и подвижные элементы в бюрократической системе Японии. Япония-2000: Консерватизм и традиционализм. М.: Восточная литература, 2000. С. 60-78. [Molodyakova E. V. Stable and Moving Elements in the Bureaucratic System of Japan. Japan-2000: Conservatism and Traditionalism. Moscow: Vostochnaya Literatura, 2000. Pp. 60-78 (in Russian)]. 
5. Полхов С. А. Культурное восприятие коррупции в Японии. Мировой опыт борьбы с коррупцией. М.: Трансперенси Интернешнл, 2014. C. 138-141. [Polkhov S. A. Cultural Perception of Corruption in Japan. World Experience in the Fight against Corruption. Moscow: Transparency International, 2014. Pp. 138-141 (in Russian)].

6. Сравнительное правоведение в России, Монголии, Китае и Японии-II. Материалы международной научной конференции студентов и аспирантов УланУдэ. Отв. ред. А. Ф. Онуфриенко. Улан-Удэ: Изд-во Бурятского гос. Университета, 2010. - 220 c. [Comparative Law in Russia, Mongolia, China and Japan - II. Materials of the International Scientific Conference of Ulan-Ude Students and Postgraduates. A. F. Onufrienko (Ed.). Ulan-Ude: Buryat State. University Publishing House, 2010. — 220 p. (in Russian)].

7. Швец Е. В. Некоторые аспекты международно-правового сотрудничества государств-членов Совета Европы в области борьбы с коррупцией. Журнал российского права. 2000. № 7. С. $65-73$ [Shvets E. V. Some Sspects of the International Legal Cooperation of the Council of Europe Member States in the Fight against Corruption. Journal of Russian Law. 2000. No. 7. Pp. 65-73 (in Russian)].

8. Шкапа Н. В. Стыд и вина в японской культуре. Вестник Челябинского университета. Востоковедение. Евразийство. Геополитика. Сер. 10. № 1. 2004. С. 169-173. [Shkapa N. V. Shame and Guilt in Japanese Culture. Journal of the Chelyabinsk University. Oriental Studies. Eurasianism. Geopolitics. Ser. 10. No. 1. 2004. Pp. 169-173 (in Russian)].

9. Реформирование системы государственного управления: зарубежный опыт и Казахстан. Алматы: КИСИ при Президенте Республики Казахстан, 2005. — 276 с. [Reforming the Public Administration System: Foreign Experience and Kazakhstan. Almaty: Kazakhstan Institute for Strategic Studies, 2005. — 276 p. (in Russian)].

10. Davies R. J., Osamu Ikeno. The Japanese Mind: Understanding Contemporary Japanese culture. Clarendon: Tuttle Publishing. 1st edition. 2002. — 280 p.

11. Pickworth J., Williams D. Bribery and Corruption. 1st ed. London: Global Legal Group Ltd, 2012. - 232 p.

12. Кансэйданго ва надзэ хэранай? Нюсацу футё кайхига мокутэкино «сингата» мо тодзё (Почему не сокращается число случаев кансэйданго? Новые формы сговора в целях недопущения аннулирования тендеров). Еженедельное издание Сюкан даямондо. URL: diamond.jp/articles/-/87077 (дата обращения 02.04.16).

13. Коррупция - излечимая болезнь? High School of Economy. URL: https://www.hse.ru/news/1163621/88978114.html (дата обращения 08.04.16).

14. Коррупция в японском исполнении. Свободная пресса. URL: svpressa.ru/society/article/53869/ (дата обращения 10.04.16). 
Японии. https://www.dpj.or.jp/article/manifesto2009 (дата обращения 11.04.16).

16. На «восходе» взяток не берут: Александр Панов о коррупции в Японии. PASMI.RU Первое Антикоррупционное CMИ. URL: http://pasmi.ru/archive/89726 (дата обращения 10.04.16).

17. Нюсацу данго надо канъёкои босихо ни цуитэ (О законе о противодействии сговору при проведении государственных тендеров). Комитет по обеспечению справедливых торговых сделок Японии. URL:

www.jftc.go.jp/dk/kansei/kanyoboushi.files/kanseileaflet02.pdf (дата обращения 13.03.16).

18. Опыт законодательного обеспечения общественного и парламентского антикоррупционного контроля в некоторых государствах мира. Сервер юридической информации. URL: http://www.jk.ru/analiticheskajainformatsija/antikorruptsionnyjj-kontrol-v-nekotorykh-gosudarstvakh-mira/ (дата обращения 08.04.16).

19. От лидерства чиновников к лидерству политиков. Ассоциация японоведов. Межрегиональная общественная организация. URL:

$\underline{\text { http://japanstudies.ru/index.php?option }=\text { com content } \& \text { task }=\text { view\&id }=305 \& I t e m i d=59}$ (дата обращения 08.04.16).

20. Хэйсэй 27 нэн кэйсацу хакусё токэйсирё (Белая книга Главного полицейского управления Японии за 2015 г. Данные статистики). Главное полицейское управление Японии. URL: www.npa.go.jp/hakusyo/h27/toukei/02/05.xls (дата обращения 10.04.16).

21. Corruption Perceptions Index 2015. Transparency International. URL: http://www.transparency.org/cpi2015 (дата обращения 26.04.16).

22. The Government of Modern Japan: The Japanese Bureaucracy. Retirement: Amakudari. Asian Topics. URL:

http://afe.easia.columbia.edu/at/jp_bureau/govtjb09.html (дата обращения 10.04.16). 


\title{
Characteristics of Economic Corruption in Japan
}

\author{
Anastasia A. Melnik \\ State Academic University for Humanities (GAUGN) \\ Russian Federation, Moscow
}

\begin{abstract}
This article describes different kinds of corruption and uprising of contemporary corruption party-bureaucratic system of Japan. Briefly described current situation, mechanics of corruption and it's negative impact on Japanese economy and attuite of modern society to business and common everyday corruption.
\end{abstract}

Keywords: corruption, iron triangle, amakudari, kansei dango

Date of publication: 31.07 .2020

\section{Citation link:}

Melnik A. Characteristics of Economic Corruption in Japan // Oriental Courier. - 2020. - Issue 1-2 C. 29-37 . URL: https://oriental-courier.ru/s268684310010362-6-1/. DOI: $10.18254 / \mathrm{S} 268684310010362-6$ 